\title{
GRAMÁTICA EN EL NIVEL SUPERIOR. AULAS PERMEADAS DE SENTIDOS
}

\section{Grammar at the higher level. Classrooms permitted of senses}

\author{
Raquel Alarcón* \\ Universidad Nacional de Misiones \\ raquelalarcon58@gmail.com
}

Palabras clave

gramática;

semiótica;

fronteras;

enseñanza;

reflexión metalingüística

\section{Keywords}

grammar;

semiotics;

borders;

teaching;

metalinguistic reflection

\section{Resumen}

El presente artículo pretende compartir algunas dinámicas de las aulas de gramática del español, entendidas como ambientes de enseñanza y de aprendizaje en los cuales los contenidos específicos de la asignatura se entrecruzan con categorías teóricas y metodológicas del campo de la semiótica, permitiéndonos poner de relieve las significaciones y los sentidos de la lengua en uso. Nuestras investigaciones acerca de la gramática y sus relaciones con disciplinas colindantes toman como base de análisis y reflexión piezas léxicas, sintagmas y enunciados dialectales que exhiben en materializaciones discursivas las marcas de un mestizaje cultural y lingüístico. Conceptos clave como frontera, vida cotidiana, experiencia, conversación y relatos, puestos en articulaciones con principios y operaciones de la gramática funcional -texto, contexto, opciones y recursos, interacciones, registro, actores sociales- y los fenómenos textuales de coherencia, cohesión, adecuación permiten construir una trama consistente para tamizar las dimensiones gramaticales y lexicales apoyadas en un abordaje de interoperabilidad o interfaces entre los distintos niveles o dimensiones. Favorecemos así la construcción de un dispositivo de estudio y trabajo con la lengua para justificar modos de enseñar gramática en el nivel superior desde y hacia las interacciones y los usos efectivos en diversos contextos -presenciales y virtuales-, sostenidos en reflexiones metalingüísticas y en los aportes de la pedagogía crítica.

\begin{abstract}
This article aims to share some dynamics of Spanish grammar classrooms, understood as teaching and learning environments in which the specific contents of the subject intersect with theoretical and methodological categories from the field of semiotics, allowing us to highlight the meanings and the senses of the language in use. Our research on grammar and its relationships with neighboring disciplines take as a basis for analysis and reflection lexical pieces, phrases and dialect sentences that exhibit in discursive materializations the marks of a cultural and linguistic miscegenation. Key concepts such as border, daily life, experience, conversation and stories, put into articulations with principles and operations of functional grammar -text, context, options and resources, interactions, register, social actors- and the textual phenomena of coherence, cohesion, adequacy allow to build a consistent plot to sift the grammatical and lexical dimensions supported by an approach of interoperability or interfaces between the different levels or dimensions. We thus favor the construction of a device for studying and working with the language to justify ways of teaching grammar at the higher level from and towards interactions and effective uses in various contexts -face-to-face and virtual-, supported by metalinguistic reflections and contributions of critical pedagogy.
\end{abstract}




\section{Gramática en el nivel superior. Aulas permeadas de sentidos}

...el objetivo último de todo estudio de la lengua debe ser el reconocimiento de cómo la lengua crea significados y de qué manera permite intercambiarlos.

M.A.K. Halliday ${ }^{1}$

\section{Instalación de apertura}

La gramática como disciplina del currículum en los diferentes niveles educativos ha atravesado siglos de permanencia con períodos más o menos gloriosos, más o menos marginales, de acuerdo con los enfoques disciplinares y pedagógicos que fueron relacionando la disciplina con la educación. ${ }^{2}$ Podemos decir que hoy, en el umbral de la segunda década del siglo XXI, ya no se discute ni se cuestiona la importancia de su enseñanza y el valor de tal conocimiento en las prácticas lingüísticas en general y en la formación de especialistas en lengua en particular. La cuestión o la problemática que nos ocupa pasa por el cómo de su enseñanza y en este sentido indagamos y experimentamos un dispositivo funcional para las aulas del nivel superior y de la escuela secundaria que opera sobre la base de la construcción de sentidos. Adquieren importancia en nuestra propuesta las formas dialectales propias de la zona de frontera que habitamos caracterizada por su configuración intercultural, pluriétnica, multilingüe y de complejos mestizajes.

Nuestras investigaciones en el campo de la lengua durante más de una década se han desarrollado sobre la base de articulaciones con la enseñanza en las aulas universitarias y-a través de propuestas de formación continua por medio de acciones de Extensión- con docentes del sistema educativo, sobre todo del nivel superior. Estas experiencias nos pusieron en conversación con los desarrollos teóricos, los enfoques curriculares, las formas de enseñanza de gramática y las características de las variantes dialectales de nuestra región; dimensiones que fundamentan la configuración de un dispositivo metalingüístico entramado con las interacciones y el uso efectivo situado en estos territorios de borde.

En primer lugar, vamos a desarrollar algunas categorías teórico metodológicas que ensamblamos en un tejido lingüístico-discursivo-semiótico; luego compartiremos de modo muy sucinto las operaciones de base de la propuesta pedagógica y los modos en que la misma se sostuvo en la modalidad virtual durante la pandemia; finalmente dejaremos planteadas algunas reflexiones de síntesis.

1. Citado por Menéndez, 2006, p. 9.

2. No es intención desarrollar acá la historia de la gramática en la educación. Remitimos a los vastos estudios y publicaciones de referentes del campo en el país (Giammatteo y Albano; Gaspar y Otañi, Di Tullio y otros). 


\section{La vida cotidiana, el punto de partida}

Partimos de la consideración de que el lenguaje es una práctica absolutamente relacional que "se aprende inmerso en una esfera cultural, en un clima biosemiótico de costumbres interconexas de significaciones y sentidos profundamente correlacionados" (Camblong, 2014, p. 179). Ese aprendizaje se da en los universos de la vida cotidiana de cada uno de los estudiantes que habitan nuestras aulas y aun cuando han atravesado -o han sido atravesados- por años de escolaridad y de aprendizaje formal de la lengua, sus enunciados conservan huellas, ecos o surcos de aquellos que han permeado sus historias y las de sus comunidades y conservan además marcas de las estructuras lingüísticas de origen.

Entender los aprendizajes como experiencias en continuidad nos permite recuperar y reusar la categoría de frontera como espacio inter, donde la vida está aconteciendo todo el tiempo, donde los movimientos se caracterizan, según nuestra semióloga amiga por:

lo heterogéneo, los cambios, las oscilaciones, los desvíos de las reglas, las mezclas, las traducciones habilidosas y amañadas al uso, las paradojas de su mera existencia proteica y las rebeldías de sus estratagemas, [que] nos hablan de un mundo-otro, de un espacio resbaladizo y difícil de asir. (Camblong, 2014, p. 187)

Esta descripción semiótica de las dinámicas de frontera nos ofrece categorías para operar en el campo de la gramática en uso que se materializa en los textos. ¿Cómo capturar esas formas-otras, que son en realidad, formas-nuestras de decir, formas-propias de contar el mundo, de conversar, de construir referentes, de expresar subjetividades? ¿De qué manera modelizar construcciones para desarrollar metalenguajes que partan de los usos y regresen siempre a ellos? ¿Con qué estrategias desplegar en el aula una red/ un montaje que nos muestre y permita analizar las oscilaciones, los desvíos, las mezclas, las paradojas, las rebeldías? ¿Con qué reglas operar en esos juegos del lenguaje amañados? ¿Qué dispositivo proponer para enseñar y aprender gramática en un espacio tan resbaladizo y darles legitimidad a las diferencias?

Para recrear, instalar, arrastrar los acontecimientos de borde al centro vital del espacio del aula de gramática apelamos a la conversación, esa vieja práctica semiótica que se desarrolla en el continuo del bla, bla, bla tomando formas genéricas diversas: relatos, descripciones, chistes, diálogos, explicaciones, etcétera. ¿Y acerca de qué conversamos? De aquellos temas vitales sobre los cuales todos tenemos algo que decir: los trabajos, las comidas, las fiestas, los caminos, las creencias populares, lo que es habitual o extraordinario en las comunidades de cada uno; es decir, aquellos protocolos o escenas cotidianas que se dicen y se cuentan en la variedad de lengua en que suele la gente hablar con los vecinos conservando así las memorias ancestrales. Memorias que se repiten -siempre iguales pero distintas- en ritmos, movimientos, desplazamientos, vivencias, rituales, expresadas en dialecto cotidiano y vecinal. Coincidimos con Camblong en definir al dialecto coloquial como la "variante del español argentino-estándar con presencia mixturada de guaraní y portugués, como emblema que condensa el sentido de costumbres muy antiguas y resistentes" (2014, p. 82). 
El continuum discursivo dialectal despliega en el aula esas modalidades lingüísticas híbridas; amalgamas morfosintácticas extrañas; ensambles de piezas léxicas en asperón y basáltico; ${ }^{3}$ giros y frases mixturadas, en un ritmo cadencioso manso y tranquilo; y cada tanto alguna muletilla o expresión dialectal típica balizando o anclando la expansión sintagmática. En muchos casos, las producciones requieren explicaciones, desarrollos, mecanismos de traducción para favorecer la interpretación, la inter-comprensión.

Un hilo lleva a otro y la urdimbre y el entramado se instalan por medio de una gramática resultante de opciones que cada alumno/a-usuario/a decidió concretar en enunciados. El laboratorio gramatical nos habilita a poner fronteras en ese continuum, cada deslinde es un discontinuo para identificar las unidades paradigmáticas de que dispone la lengua, las reglas que subyacen, las dimensiones o fases del estudio funcional, el sentido de la reflexión metalingüística. Y luego, volver al continuo para seguir potenciando sentidos en nuevos tejidos discursivos.

A continuación, compartimos algunas operaciones estratégicas de nuestras secuencias didácticas que tienen por objetivo el estudio reflexivo de la gramática en uso.

\section{Un dispositivo "inter" de enseñanza-aprendizaje}

Los desarrollos investigativos del proyecto "Gramática en fronteras interdisciplinares (Grafin)"4 desde sus inicios se han sostenido en las articulaciones con la enseñanza y la transferencia a través de la extensión, la participación en eventos científicos y la formación de recursos humanos; cada ámbito potencia la consistencia de un modus de abordaje de la lengua en uso tanto como objeto teórico multidimensional cuanto como objeto de enseñanza que requiere particulares mediaciones.

Entendemos a la gramática como disciplina científica dentro del campo de la Lingüística actual que estudia el sistema de la lengua, sus unidades, las reglas de funcionamiento y organización y las operacionalizaciones en textos concretos, unidades discursivas de uso realizadas por hablantes en interacciones socio-histórico-culturales.

En el marco de esta conceptualización se construye un artefacto teórico metodológico asentado sobre el diálogo y la cooperación entre la lingüistica formal-estudio de los mecanismos de la lengua a partir de modelizaciones- y el paradigma funcionalista-consideración de las lenguas desde su finalidad comunicativa y su carácter histórico y sociocultural (Ciapuscio, 2009). Ponemos en contactos estos enfoques con las categorías semióticas que venimos exponiendo y los fundamentos de la pedagogía crítica.

\footnotetext{
3. Asperón y basáltico es el modo en que Camblong caracteriza el mestizaje lingüístico que amalgama formas castizas (alusión a la dura piedra basáltica) con formas del guaraní (aludido como asperón, la maleable roca arcillosa).

4. 2010-2012: "La Gramática en fronteras (inter)disciplinares. Del metadiscurso a los abordajes semióticos" (Código 16H294). 2013-2016: "La Gramática en fronteras (inter)disciplinares II. Entramados semióticos" Parte II. (Código 16H364).

2017-2021: "La Gramática en fronteras (inter)disciplinares III. Configuraciones mestizas de la lengua en uso en Misiones". (Código 16H462).
} 
¿Por qué hablamos de un dispositivo "inter”? Justamente porque asumimos una posición en las fronteras geopolíticas, en los bordes de las disciplinas, de los ambientes, de las lenguas, de las operaciones; porque somos enunciadores situados en un espacio intercultural, de pasajes continuos e incesantes y en tal perpetuum mobile ocurre, acontece el uso verbal y su gramática.

A continuación, compartimos de manera muy acotada maniobras y procedimientos inter que, apoyados en un enfoque ecléctico, proponen interoperabilidades léxico-gramaticales, semánticopragmáticas, discursivo-semióticas.

\subsection{Semiosferas de la vida cotidiana y géneros discursivos primarios}

Invitar a conversar implica la contrapartida de invitar (y predisponerse) a escuchar; y en un aula de gramática además, escuchar como gramáticos, esto es, sensibles y atentos a las variaciones, a las formas, a las secuencias desarrolladas, a los corrimientos sutiles y perpetuos, a las repeticiones y las diferencias; opera ahí un procedimiento de deslindes aleatorios y una traducción permanente para interpretar sentidos identificando los hilos que se entraman por debajo o por detrás del tapiz heterogéneo de las voces, donde fermenta y burbujea un ancestral mestizaje. Ante cada marca o deslinde, otro corrimiento, otro borde incluido, otra frontera desdibujada. Para "controlar" en algún aspecto estas maniobras, necesitamos conocer las unidades de análisis, administrar las reglas de combinaciones, identificar las dimensiones de abordaje del objeto, aprender la teoría gramatical.

La conversación sobre tópicos de la vida cotidiana nos ha permitido configurar en las aulas un increíble y variado conjunto de semiosferas, cuyas particularidades de pensamiento y acción se expanden en géneros discursivos primarios: relatos, anécdotas, diálogos breves, frases humorísticas, fórmulas de saludos, pronósticos, recomendaciones, instrucciones, consejos, onomatopeyas, chascarrillos, muletillas, etc.

Los diagnósticos realizados con cada grupo-aula como así también los avances en líneas de investigación de los integrantes del equipo y los sucesos culturales emergentes orientan los intereses y las semiosferas sobre las que focalizamos con las distintas cohortes las secuencias de trabajo. Cada itinerario formativo nos provee de insumos, ejemplarios, corpus y datos que vuelven a la investigación, se transforman en materiales de cátedra, en producciones científicas, en nuevos proyectos de extensión. Cuando advertimos que alguna semiosfera resulta muy proteica y potente la volvemos a proponer en recreadas experiencias lo cual nos habilita trabajos comparativos, organización de series, caminos rizomáticos. Los contenidos y sus correlatos van orientando las decisiones metodológicas.

Los enunciados producidos y recuperados, piezas lingüísticas propias de los intercambios conversacionales, se transforman en modelizaciones de lengua en uso que sometemos al análisis, la descripción y la explicación por medio de mecanismos de interoperabilidad entre unidades y dimensiones lexicales, morfosintácticas, semánticas, pragmáticas y semióticas. Los movimientos de interfaz se constituyen en la base para la reflexión sobre las particulares formas de una gramática cuyas características se exhiben en el juego de las significaciones y los sentidos de una continuidad vital. 
Intentamos describir sucintamente algunas de estas operaciones a través de ejemplos recogidos de algunas semiosferas específicas como las plantas, la toponimia, los trabajos y las creencias, para intentar a partir de estos casos particulares una caracterización somera de la gramática de uso. ${ }^{5}$

\subsection{Caminos lexicales}

Como sabemos, los textos entraman sentidos en el inter-juego léxico gramatical, así, por ejemplo, cuando ingresamos en la semiosfera de las plantas pudimos deslindar subconjuntos o mundos plantarios: las flores, los árboles, las plantas medicinales.

La conversación se dispara a partir de un corpus de imágenes -fotografías, dibujos, videos- de diversos ejemplares de la flora de la región, ante los cuales los estudiantes van nombrándolos, y advierten las diferencias de nombres; comparten anécdotas, creencias, recomendaciones y en ese discurrir "se van imbricando con el español las dos vertientes a las que Amable H. denomina 'sustrato guaraní e 'influencia del brasilero’ (Simón, 2018), ${ }^{6}$ además de realizaciones provenientes de contactos con lenguas inmigrantes.

Basta que alguien nombre el ejemplar para que otro proponga un sinónimo y otros comenten el sentido práctico del uso. Así nos enteramos de para qué dolencias sirven: la manzanilla, el ka’aré o paico, el guavirá, el jaguarete ka'a o carqueja, el ambay, el kokú y el palosanto, entre otros.

Simón acopia en relación con esta semiosfera ejemplos de plantas que alternan el nombre en guaraní con otras formas como ka'a he’e (estevia); ibirapitá (cañafístola); o denominaciones con influencia del brasilero como maria preta o fumo bravo.

$\mathrm{Al}$ indagar sobre creencias o leyendas de los lugares de residencia de los estudiantes se habilita en el aula el ingreso a una semiosfera mágica que da vida a personajes como el yasy yateré; el curupí; los fantasmas, aparecidos y poras; el mao pelada. En el despliegue de este tópico, una alumna de la zona lindante con Brasil contó el significado de la borboleta preta como anunciadora de desgracias, hubo que traducir varias palabras y sintagmas para comprender que hablaba de la mariposa negra; en continuidad otra leyenda oponía la mariposa como símbolo de buenas noticias y no faltó quien asociara el relato con una antigua historia traída por su oma de la lejana Europa.

La geografía diversa y los límites plurales de nuestra cartografía introducen referencias de una toponimia híbrida, ${ }^{7}$ de lugares cuyos nombres se pliegan sobre sonidos, murmullos y evocaciones

5. Contamos en nuestros ejemplarios y corpus con una abundante muestra de enunciados devenidos de semiosferas cotidianas: la feria franca, los juegos, los espacios virtuales de compra-venta, el agua, el fuego, las fiestas de San Juan, entre otros.

6 Simón G. en el apartado I, Recorridos por el léxico. Desde las denominaciones de plantas hasta los campos léxicos de Coseriu del capítulo "Gramática en uso. Construcciones teórico metodológicas", del libro Alternativas semióticas en la enseñanza de la lengua. Relatos de formadores, explica que Hugo Amable en Las figuras del habla misionera denomina brasilero a la influencia del portugués brasileño.

7. Resultados de nuestras investigaciones en esta dimensión del léxico, se pueden leer en el artículo "De lugares y de gentes en la frontera intercultural de Misiones. Hibridaciones lexicales” (Alarcón, 2017). 
históricas de guaraníes, jesuitas, evangelizadores, colonizadores, españoles, portugueses, viajeros, inmigrantes, gobernantes intentando dejar en la nominación un trazo de su paso por esta historia de mestizajes.

Los guaraníes mbya han nominado en su lengua aglutinante lugares que encierran una perfecta descripción: Moconá (donde el diablo traga), Panambi (mariposa), Yabebiry (río de las rayas), Piray (agua de los peces), Yaboti (enredadera, maraña), Caá-Yari (diosa de la yerba mate) acentuando la sílaba aguda que le da la particular cadencia a nuestra tonada. Los nombres del santoral cristiano perviven como huellas de la misión de los jesuitas y la imposición del español en el siglo XVII, en nombres de algunos pueblos: Apóstoles, Candelaria, Concepción, San Ignacio, San Javier, San Pedro, y también dan cuenta de los primeros cruces culturales: San Ignacio Miní-San Ignacio Guazú, maniobra que no se abandonó pese a la expulsión de los jesuitas en 1767.

Con el proyecto de conformación del Estado Nacional y colonización y la explotación de las tierras (S XIX) llegaron oleadas de inmigrantes europeos; polacos, alemanes, rusos, ucranianos, suecos, suizos, italianos comenzaron a asentarse en los primeros pueblos y colonias, cuyos nombres aluden a los puertos precarios sobre el río Paraná en los que desembarcaban: Puerto Iguazú, Puerto Esperanza, Puerto Rico, Puerto Libertad, Puerto Piray, en los que se mantiene la conjunción del español con el guaraní, lenguas a las que comienzan a integrarse las de los inmigrantes. De esta época y estos proyectos inmigratorios quedan topónimos como: Eldorado (fusión morfológica el+dorado) en clara alusión a las leyendas sobre la ambición áurea de los conquistadores; Polana, una colonia fundada por polacos que en esa lengua original significa "claro en el bosque", en referencia a la construcción del nuevo hábitat en medio la selva; Wanda, localidad del alto Paraná que según sus habitantes rememora el nombre de una princesa polaca. El territorio se poblaba de inmigrantes mientras la explotación del "oro verde" (yerba mate) se concretaba por el trabajo de los tareferos criollos y "el canto triste del pobre mensú", ${ }^{8}$ memoria que se recupera en nombres de colonias y parajes como Caá-Yarí, Barbacuá (lugar donde se secaba la yerba) y Urú (nombre del encargado de mover permanentemente las hojas en los hornos).

Vimos hasta aquí una toponimia léxica bajo la cual respira la historia. Del mismo modo podemos rastrear en los hidrónimos de la provincia las palpitaciones de las vecindades de uno y otro límite. En toda la franja de la costa del Alto Uruguay vamos encontrándonos con cauces de agua cuyos nombres remiten a términos en brasilero: Laranjeira (naranjo), Samambaya (helecho), Pesiguero (duraznero), Tararira (pez voraz), Agua Dos Porcos (agua de los cerdos), Macaco (mono) y su diminutivo Macaquito/Macaquiño (monitos), Chafariz (fuente pública). Los diminutivos de esta vecindad imponen su forma con el sufijo del portugués “-iño” (Saltiño, Capioviciño) pese a los intentos de argentinizarlos. En la desembocadura sobre los barrancos del Uruguay, los bancos de arena son designados como barra; más de diez topónimos compuestos con esta palabra encontramos en estas costas: Barra Bonita/ Mansa/ Alegre/ Grande/ Preta/ Tuerta/ Saltito/ etc.

8. Ramón Ayala, poeta y compositor misionero - cuyo nombre se asigna a un arroyo del norte de la provincia- homenajea al mensú en una canción (ritmo de gualambao) homónima. 
Si cambiamos de ruta y bordeamos el río Paraná, lindante con Paraguay, a cada rato nos encontramos con nombres de arroyos que dan cuenta de esa vecindad de lengua aglutinante: Aguapey (arroyo de los camalotes), Aguaray (agua de los zorros), Caraguatay (arroyo de los caraguatá/cardos), Piray (arroyo de los peces), donde advertimos el uso del sufijo “y” para designar agua/arroyo/río de/. Otros frescos remansos en esta ruta son: Teyucuaré (cueva o lugar de lagartos); Mbopicuá (lugar o cueva de murciélagos); Paticuá (lugar de patíes), ejemplos en los que vemos la partícula "cua" que significa lugar de o cueva de, muy común en los topónimos de origen guaraní. En honor a la abundancia de la fauna y de la flora también encontramos nombres que remiten a las distintas especies: GuabirálGuavirá (árbol de frutos amarillos), Guaraipo (abejas), Guatambú (árbol de madera dura), Mbarigüi (mosquito), Tamanduá (oso hormiguero). En varios casos los arroyos de idéntica denominación son diferenciados por el agregado de los adjetivos "guazú" (grande) y "miní" (chico) que adjuntos al nombre conforman una pieza léxica compuesta (Piray Guazú/Miní, Itaembé Guazú/Minì). El guaraní cuenta también con el sufijo diminutivo “i” con el que se forman algunos topónimos (Cabure-i: buho pequeño, Inanmbu-í: perdiz pequeña).

Y del léxico a la morfología, un paso en continuidad, para compartir otra posibilidad de sistematización léxico semántica en la reflexión gramatical.

En el mismo artículo mencionado, Simón G. (2018) desarrolla una interesante reflexión sobre los adjetivos de la variedad dialectal titulando el apartado con un enunciado híbrido: "Baita adjetivo cate”, en el cual amalgama brasilero (grande), más español, más guaraní (elegante).

Hemos construido una interesante serie de verbos de uso típico con sufijos terminados en -ear que nos permitieron armar un paradigma:

llavear (< llave), guampear (< guampa), tonguear (< tongo), machinguear (< machinga < macho), cabezudear (< cabezudo), arisquear (< arisco), malditear (< maldito). Y en esta serie de verbos provenientes de nombres, podemos ubicar también randapear, casi un neologismo formado por un extraño procedimiento -¿metonímico? - asociado con la pronunciación del producto "Round Up" utilizado para pulverizar las plantaciones de tabaco. Podemos incluir en este grupo al verbo judear muy usado en la región para expresar la maldad de Judas y denunciar abusos de poder en las relaciones asimétricas. Camblong expone en relación con el uso de este verbo arcaico "que ha quedado desde la colonia, como un diamante perdido que no se encuentra en ningún otro lugar en el que se hable español” (2014, p. 35).

En esta línea de juegos derivativos nos resultan familiares los neologismos TIC como googlear, surfear, feisbuquear, tuitear, bloguear, formas que aparecen entremezcladas en las hibridaciones de sentidos que se despliegan en las aulas.

La competencia léxica está asociada a la morfológica y esta a la sintáctica, de modo que avanzamos en el continuo lingüístico para ver unos ejemplos del habla coloquial sobre los mestizajes sintagmáticos. 


\subsection{Sintagmática mestiza}

Al desarrollar los ejemplos relacionados con el léxico entrecruzamos operaciones de morfología derivativa y flexiva con lo cual ya nos conectamos con articulaciones sintácticas, de modo que en este apartado compartiremos unos ejemplos de enunciados relacionados con las interacciones del trabajo de las paseras. ${ }^{9}$ Los estudiantes relatan historias/ anécdotas familiares de mujeres de sus familias dedicadas a la actividad del "pase", o de las que conocen porque semanalmente recorren los barrios ofreciendo sus productos. Junto al léxico propio que va haciendo aparecer ese mundo: paso, control, mercadería, puente, cambio, trabajo femenino, las piezas léxicas encadenan sintagmas que arman relatos y escenas conversacionales situadas en espacio-tiempo de pasajes. Los enunciados que compartimos a continuación fueron tomados de los relatos de estudiantes y del audiovisual "Un paso con historia" (Zanotti) ${ }^{10}$ en el cual varias mujeres testimonian su cotidiana experiencia:

a) Y así pasan nuestros días, mi reina, a veces tenemos suerte y el aduanero nos contempla [perdona/ ayuda] pero también nos suelen quitar lo poquito y ahí 'masiado nos argelamo' mismo.

b) "Mi clienta me pidió un saco para la escuela y ahí gano liviano y me hallo."

c) Dame dos yogur de coco y petei ${ }^{11}$ de frutilla.

Solamente analizaremos algunas características dialectales de estas muestras riquísimas que en su sintética brevedad concentran o apiñan la dinámica turbulenta de la semiosfera del trabajo de paseras. Estos enunciados recuperados de la oralidad, constituyen piezas discursivas entramadas en el cruce y el trabajo en el pase que conllevan un fuerte sentido pragmático, un enclave en la enunciación a la vez que habilitan la reflexión sobre las operaciones discursivo gramaticales.

El trabajo es el eje de la acción, en el escenario del paso se distribuyen los protagonistas, mediante vínculos e interacciones en torno de la mercadería, las ganancias, la supervivencia.

El ejemplo a) refiere al primer movimiento: pasar con la mercadería sorteando el obstáculo del control aduanero, el representante del poder que a veces perdona o ayuda (contempla) y otras, censura y castiga (suele quitar) produciendo en ellas la reacción de alegría (suerte) o de mucho enojo (nos argelamos).

El inicio del enunciado con el marcador ilativo " $y$ " muy frecuente en el uso dialectal, "subraya el continuum en el que se inserta el discurso y su enganche con la palabra del otro" (Camblong, 2014, p. 36) reforzando el movimiento del "ir", "venir", "traer” y "llevar" más la sostenida prolongación de los gerundios, propios de esta semiosfera.

La corriente discursiva incesante va deslizándose en cada frase, en cada verbo (des)ordenador de argumentos, en una sintaxis cadenciosa que cada tanto se baliza con una muletilla irremplazable

9. Paseras: nombre que reciben las mujeres trabajadoras en el cruce o paso fronterizo dedicadas a traer y llevar mercaderías típicas. En la cátedra trabajamos en profundidad esta dinámica al abordar la semiosfera de los trabajos de la zona.

10. Diálogos del audiovisual de Ana Zanotti sobre las paseras Uno de los cuatro capítulos que integran la serie documental Escenas de la vida en el borde.

11. Petei significa uno (1) en guaraní. 
que colabora en las segmentaciones aleatorias: mi reina, mismo, (entre otros como nambrena, ñandeyara, eâ).

El ejemplo b) es una muestra de la siguiente escena, segundo movimiento, en la cual se concreta la transacción con la clienta, y como el "saco" (abrigo) es una mercadería "liviana" (en relación con los pesados canastos de frutas y verduras que suele transportar), su ganancia es "liviana", de poco esfuerzo físico, lo que le produce un "hallarse", una alegría propia de quien lo ha logrado en primera persona (Mi clienta, me pidió, me hallo).

Y el ejemplo c) refiere al movimiento tres, la continuidad de la tarea en la posibilidad de intercambiar su rol y con el dinero obtenido, comprar mercadería (yogurth) para volver a cruzar de regreso al otro lado: la transacción comercial se negocia diglósicamente (dos de coco y peteí de frutilla) en dos sintagmas paralelos pero con un léxico mezclado.

Tanto en a) como en b) observamos el uso de la forma adverbial “ $y$ ahi” funcionando como una pieza témporo-espacial que ubica al enunciador en el enclave de su propia enunciación.

Cuantas más variedades de uso habilitemos más opciones estarán circulando en el laboratorio áulico, ya sea asociadas con una misma semiosfera o con otras colindantes, más recursos para el análisis y las explicaciones léxicas, sintagmáticas, proposicionales, de cláusulas o párrafos, para la construcción de metalenguajes y reflexiones sobre las operaciones en las que las unidades formales sostienen y son sostenidas por la continuidad discursiva de los eventos de acción.

Las modalizaciones de los recortes discontinuos que realizamos constituyen, al igual que los enunciados-textos, fenómenos isomórficos que funcionan como una especie de mónada en la que se realizan las formas gramaticales, más o menos estables, de las esferas a las que representan o en las cuales circulan, permitiéndonos por una parte, la descripción de la variedad dialectal -por las repeticiones y recurrencias- y por otra, la posibilidad de variación y diferencia, la capacidad de significar y disparar sentidos distintos en cada ocasión particular mediante nuevas producciones textuales.

\subsection{La virtualidad, una nueva frontera}

En este apartado expondremos algunas decisiones didácticas tomadas en la enseñanza virtual durante el período de ASPO iniciado en marzo del 2020 debido a la pandemia originada por el COVID-19.

Re-pensar y re-significar las prácticas habituales presenciales para diseñar secuencias mediadas por las tecnologías de la información y la comunicación significó una modificación muy profunda tanto en la selección de contenidos cuanto en las propuestas de enseñanza y aprendizaje. Al mismo tiempo que lo hacíamos, fuimos aprendiendo a utilizar las herramientas TIC y a desarrollar criterios para la utilización más adecuada desde el punto de vista de los objetivos y de las posibilidades de los estudiantes para acceder a las plataformas y enfrentar sus aprendizajes con la mayor autonomía posible. 
El problema pedagógico que nos planteamos en la cátedra de gramática fue: ¿Qué contenidos priorizar? y ¿Cuál será la mejor manera de enseñarlos en estas nuevas condiciones? Como punto de partida, acordamos algunos principios ordenadores:

- Incluir contenidos nodales, tanto por su significatividad en el programa de la materia cuanto por la posibilidad de establecer relaciones, de expandir significaciones.

- Explicitar en lenguaje didáctico los diferentes pasos propuestos o secuencias de construcción, reiterando los objetivos, aclarando el porqué de cada actividad y ofreciendo diversas alternativas para llegar a las metas.

- Propiciar instancias de evaluación permanentes y diversas.

- Ofrecer espacios de reflexión sobre la vida cotidiana-relacionados con los contenidos- y el modo en que estaban/están sobrellevando en sus familias y entornos la experiencia del confinamiento social.

- Cuidar la comunicación en sus varias dimensiones: personales, institucionales, entre los estudiantes y entre colegas, mediante el uso de formas verbales, no verbales, multimediales, sincrónicas, asincrónicas, todas las que están a nuestro alcance y al de los estudiantes.

- Atender particularmente los procesos y los tiempos individuales y de los grupos diversos.

Sobre la base de estos postulados fuimos proponiendo el desarrollo de los temas, adecuando las estrategias que en la presencialidad nos resultaban significativas y creando nuevas. Las secuencias didácticas gramaticales orientadas a un aprendizaje recursivo y espiralado continuaron respondiendo a intencionalidades específicas como:

- Comprensión teórica del tema: lectura de fuentes con guías orientadoras, observación de videos, exposiciones explicativas grupales, búsqueda de información, participación en encuentros sincrónicos, evaluación de materiales de cátedra, etc.

- Identificación de dimensiones y unidades de análisis: ejercicios de señalamiento, selección, comparación, etc.

- Análisis y manipulación de construcciones gramaticales: deslindes de unidades, reformulaciones, análisis de funciones, alternancias, permutaciones, corrimientos, producción, operaciones inter.

- Utilización de las construcciones en la producción textual: producciones de planes, borradores, versiones a partir de las opciones lingüístico-discursivas.

- Reflexión metalingüística: comentarios, explicaciones y justificaciones de los usos gramaticales efectuados.

- Reflexiones sobre la materialización de las formas en el uso dialectal: comparaciones de formas estándares con dialectales, valorización del lenguaje de fronteras. 


\subsection{1. ¿Cómo enseñamos y aprendimos en línea las subordinadas adjetivas? ${ }^{12}$}

A partir de la concepción de lenguaje que sostiene la cátedra, entendemos a la gramática situada y funcionando en contextos de uso significativos y planteamos un abordaje teórico y reflexivo de las opciones formales y reglas de la lengua como posibilidades de materializarse en producciones de usuarios que interactúan en contextos comunicativos diversos. Estas conceptualizaciones de base se traducen en una metodología de enseñanza que intenta hacer de la forma un contenido, esto es, presentar el desarrollo de cada tema de la gramática formal en un contexto de uso en el cual se generan enunciados con significados y sentidos propios de la semiosis de esa trama.

En el caso particular de la experiencia comentada elegimos como eje o tópico la llegada de la primavera (la clase inició justamente el lunes 21 de septiembre) y el florecer de los lapachos que es un signo natural típico de la región. El mismo en tanto fenómeno natural tiene significaciones profundas en los hábitos y las prácticas culturales de los habitantes del campo y de la ciudad. El mundo de significaciones que despliega el fenómeno "los lapachos en flor" es recogido por diferentes manifestaciones artísticas: la fotografía, la pintura, la música, la literatura; producciones que utilizamos para potenciar sentidos en nuestras clases a la vez que ampliamos el universo cultural de los estudiantes. En este caso en particular tomamos poemas, canciones y un collage de imágenes. ${ }^{13}$

Luego de dos semanas de abundante ejercitación y práctica de resolución de problemas gramaticales relacionados con las subordinadas adjetivas, presentamos las instrucciones de producción escrita con la siguiente consigna como andamio:

Realizar una producción creativa a partir de las siguientes instrucciones:

a) Buscá una imagen de tu entorno relacionada con la llegada de la primavera. Podés tomar una fotografía con tu celular o hacer un collage.

b) Escribí tres sintagmas nominales simples referidos a sujetos, objetos, espacios $\mathbf{o}$ acciones asociados con la imagen.

c) Agregá a los sintagmas elaborados, adjetivos o sintagmas adjetivales que los modifiquen.

d) Transformá las construcciones simples del punto anterior en proposiciones subordinadas adjetivas.

e) Incluí los sintagmas con subordinadas en oraciones compuestas (al menos 4).

d) Utilizá el campo lexical y las construcciones sintácticas de los puntos anteriores en una producción creativa.

Elegí uno de los géneros discursivos propuestos: postal- video breve- meme- poema-canción- texto de enciclopedia- noticia- muro de blog o de Facebook- infografía- grafitti- publicidad.

Recordá que la intencionalidad es promocionar o dar a conocer tu barrio/pueblo/ciudad, utilizando subordinadas adjetivas.

Socialización. Compartí el trabajo en el grupo de Facebook de la cátedra durante la semana próxima (hasta viernes 02 de octubre).

12. Un interesante análisis de esta experiencia fue presentado en forma conjunta con los estudiantes Nadya Manzur y Horacio Nazaruk, quienes acompañaron como adscriptos durante todo el año 2020 en la ponencia "Subordinadas en línea. Opciones para mostrar-te mi entorno cotidiano", preparada para el Foro 2020 "De la Presencialidad a la Virtualidad. Experiencias Docentes en el marco de la pandemia. FHyCS - UNaM.

13. La clase teórica puede recuperarse en el canal de Youtube: https://bit.ly/30ELQ0F. 
Más de treinta trabajos de producción fueron compartidos en el Facebook permitiéndonos, por un lado, evaluar el modo en que los estudiantes ponen en uso o en juego las construcciones y operaciones que estamos aprendiendo y, por otra parte, abren ventanas-ampliando las cuadrículas del Webex o del Zoom - a los mundos y contextos de cercanía de cada uno de ellos.

Las producciones creativas que han compartido nos permiten ponderar algunos aspectos como:

- La comprensión de las funciones de las subordinadas adjetivas como modificadores de núcleo nominal antecedente que se construyen con determinadas reglas de la sintaxis (nexos, correlación temporal de verbos, concordancia con antecedentes o consecuente, etc.).

- El uso de tales construcciones en bases textuales descriptivas que permiten dar a conocer características, propiedades de los lugares promocionados.

En relación con los mundos cotidianos de los alumnos, nos permitió saber en qué lugar de la provincia o región se encuentran; las imágenes seleccionadas o las fotografías tomadas por ellos aportan a la clase conocimientos muy interesantes acerca de fiestas populares o religiosas, producciones propias del lugar, actividades económicas y culturales, fiestas, paisajes y naturaleza típica o las intimidades de sus jardines, etc.

La utilización de variadas herramientas tecnológicas -fotografía, videos, Power Point, gifs, etc.nos informan de los grados de dominio de las TIC y las posibilidades con que cuentan para responder a consignas con intencionalidad y marcas genéricas específicas.

Finalmente, la co-evaluación se constituyó en una nueva socialización -sumada a la galería virtual del Facebook - en la cual cada uno pudo profundizar su mirada sobre el trabajo del compañero, ponderando -mediante una rúbrica- los aspectos textuales y gramaticales y colaborando con sus pares en la revisión y mejora de las producciones.

Parte de la interesante galería de postales, se comparte en el Anexo de este artículo.

\section{En los pliegues finales...}

Las fronteras son espacios de pliegues donde los finales son continuidades, posibilidades de reinicios, extensiones, indicios de nuevos hallazgos; en ese sentido consignamos acá algunos enunciados con provisoriedad de cierre y con la intención de que continuemos pensando.

Cada espacio de uso de la lengua inaugurado por conversaciones, relatos, comentarios y toda posible interacción es un laboratorio vivo donde las formas adquieren novedosas derivas despiertan en cualquier estudioso de la lengua la curiosidad por indagar qué sentidos migran y desplazan, condensan y expanden; por instalarse en tales territorios entendiendo que los metalenguajes no son un problema sino que "la cuestión finca en no volverlos una armadura que nos ahoga, un artefacto que monitorea discursos exentos de pasiones, humor y temblores semióticos que juegan con el sentido" (Camblong, s/d). 
El dispositivo áulico de enseñanza que describimos y explicamos en este texto propone una gramática de la experiencia que complementa dimensiones oracionales, textuales, discursivas y semióticas, entendiendo que es el camino para la interpretación de significados construidos activamente que exhiben en variedades dialectales la sabiduría de los lenguajes cotidianos y de la vida práctica.

\section{Referencias bibliográficas}

Alarcón R. (2018). De lugares y de gentes en la frontera intercultural de Misiones. Hibridaciones lexicales. ReDILLeT, Revista digital internacional de Léxico, Lexicología y Terminología, 1 Vol 2. https://revistas.unc.edu.ar/index.php/ReDILLeT/article/view/22259.

Alarcón R., Simón G. y Tarelli V. (2018). Gramática en uso. Construcciones Teórico-metodológicas. Alternativas semióticas en la enseñanza de la lengua: relatos de formadores (pp. 7-23). Posadas, EDUNAM.

Alarcón R., Manzur N. y Nazaruk H. (2020). Subordinadas en línea. Opciones para mostrar-te mi entorno cotidiano. Ponencia presenta en Foro 2020 de la Presencialidad a la Virtualidad. Experiencias Docentes en el marco de la pandemia. FHyCS - UNaM.

Camblong, A. M. (2014). Habitar las fronteras... Posadas, EDUNAM.

Camblong, A. M. (s/d). Lenguaje y metalenguajes (mimeo).

Casado Velarde, M. (2018). Lingüística y gramática del texto: su articulación interdisciplinar. Rilce: Revista de Filología Hispánica, 16 (247-262).

https://revistas.unav.edu/index.php/rilce/article/view/26801/22655.

Ciapuscio, G. E. (coord.) (2009). De la palabra al texto: estudios lingüísticos del español. Buenos Aires, EUDEBA.

Di Tullio, A. (2010). Manual de Gramática del español. Buenos Aires, Waldhuter.

Di Tullio, A. y Malcuori M. (2012). Gramática del español para maestros y profesores del Uruguay. Montevideo, Administración Nacional de Educación Pública, CODICEN.

Gaspar, P. y Otañi, L. (2001). Sobre la gramática. En Alvarado, M. (coord.), Entre líneas. Teorias y enfoques en la enseñanza de la escritura, la gramática y la literatura (pp. 75-111). Buenos Aires, FLACSO, Manantial.

Gaspar, P. y Otañi, L. (2004). La gramática. En Alvarado, M. (coord.), Problemas de enseñanza de la lengua y la literatura (pp. 71-99). Buenos Aires, Universidad Nacional de Quilmes.

Ghio, E., Navarro, F. y Lukin, A. (comps.) (2017). Obras esenciales de M.A.K. Halliday. Santa Fe, Ediciones UNL, EUDEBA.

Giammatteo, M. y Albano, H. (coords.) (2009). Lengua. Léxico, gramática y texto. Buenos Aires, Biblos. 
Lavandera, B. (2014). Variación y significado. Y discurso. Buenos Aires, Paidós.

Menéndez S. M. (2006). ¿Qué es una gramática textual? Buenos Aires, Litera.

Zanotti A. (1998). Escenas de la vida en el borde: Un paso con historia [documental]. Instituto Nacional de Cine y Artes Audiovisuales.

* Raquel Alarcón es Doctora en Semiótica (CEA-UNC), Mgter. en Docencia Universitaria (UNaM), Esp. en Enseñanza de ELE, Prof. y Lic. en Letras. Prof. titular regular de Gramática 2 y de Didáctica, curriculum y aprendizaje en las carreras de Letras (FHyCS-UNaM). Investigadora del Programa de Semiótica (categoría II) (SInv-FHyCS). Posee publicaciones en el campo de la alfabetización semiótica y la enseñanza de la lengua en uso. Coordinadora de la subsede Cátedra UNESCO para la lectura y la escritura (UNaM). Coordinadora del Programa de EaD, FHyCS Virtual.

RECIBIDO: $14 / 09 / 2021$

ACEPTADO: 10/11/2021 
Anexo. Producciones con subordinadas adjetivas. Octubre de $2020^{14}$
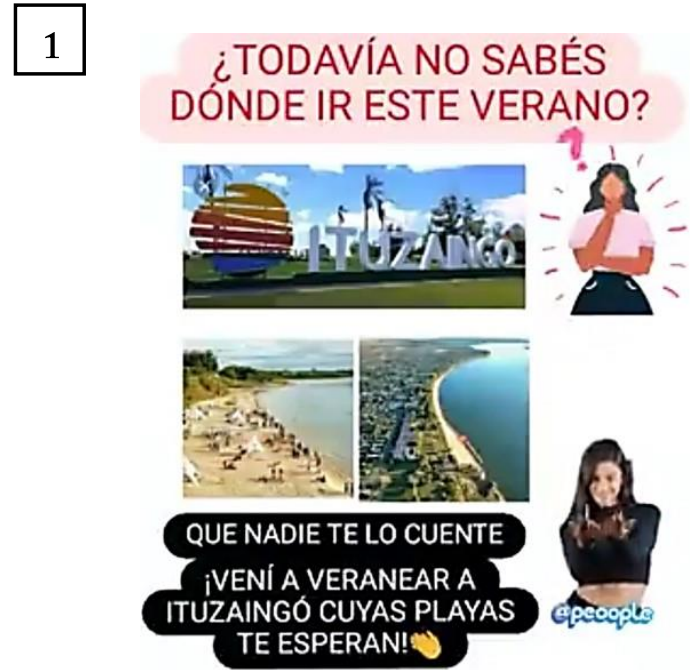

ITUZAINGÓ LA CUIDAD QUE
DESLUMBRA
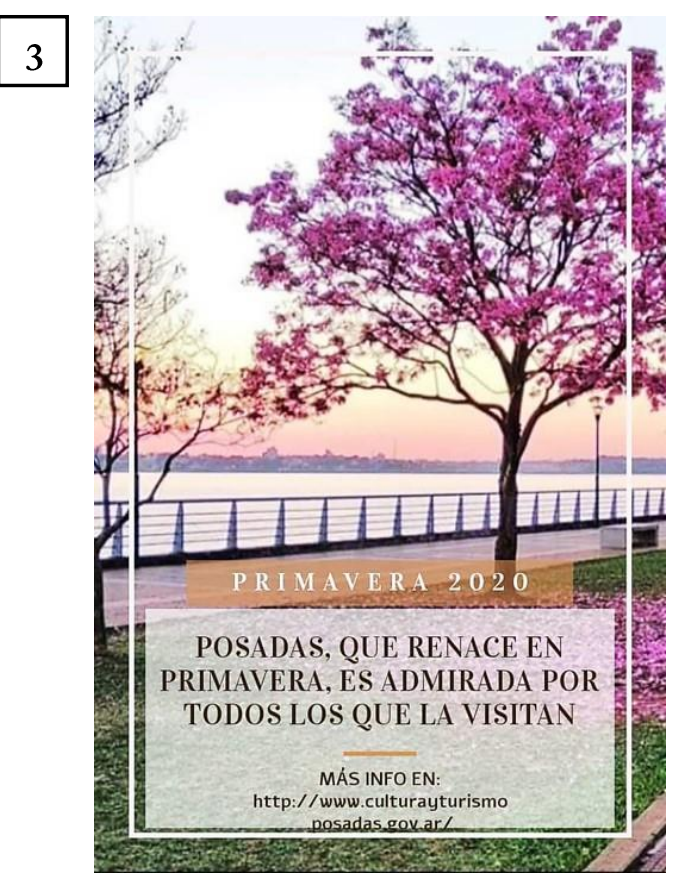
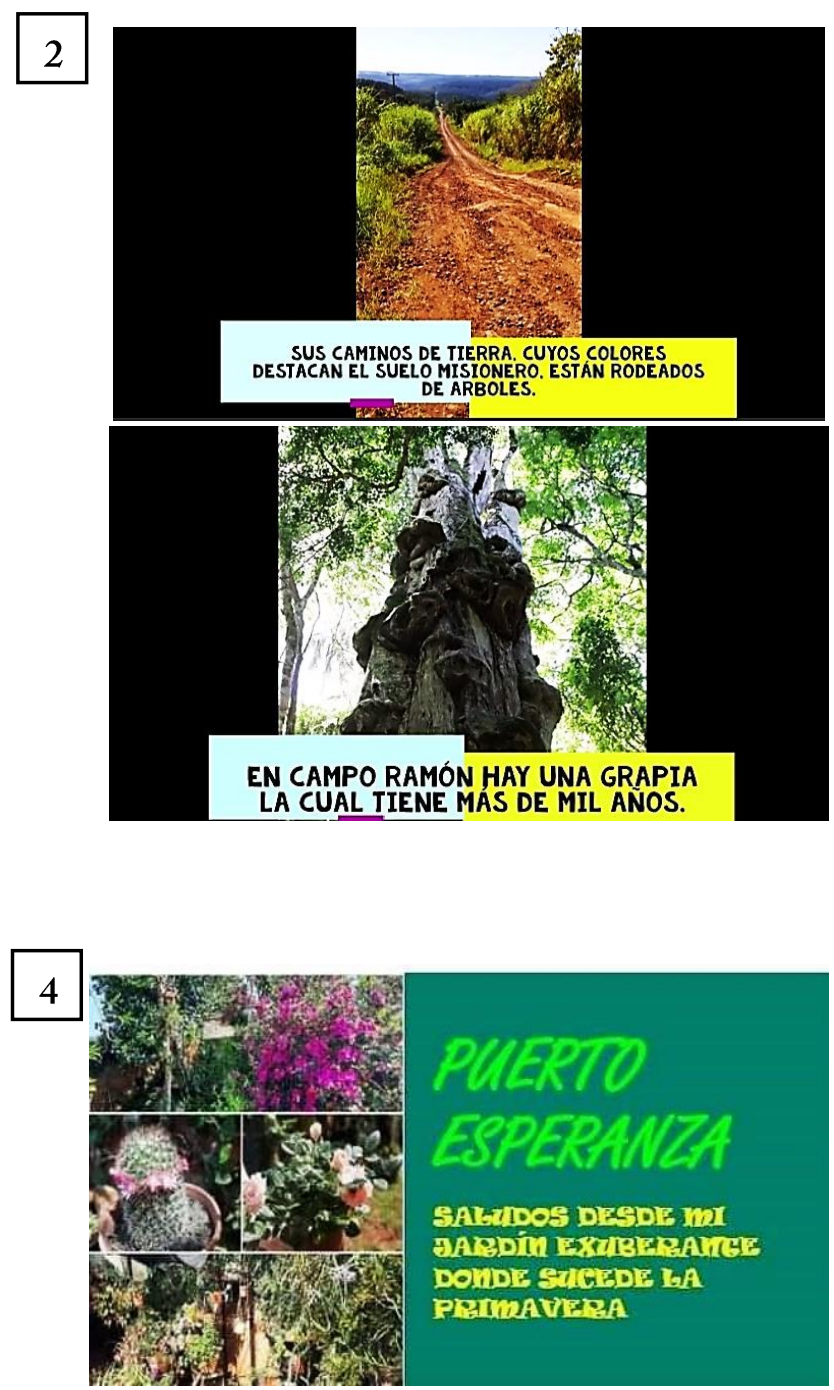

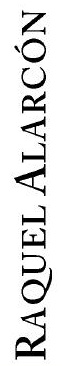

14. Alumnos autores de los textos: 1. Ángela Ferreyra. 2. Karen Daniela Bianchi. 3. Lara Granizo. 4. Belén Tarnouski. 5. Lisandra Danieli Malveira. 6. Susan Ramírez. 

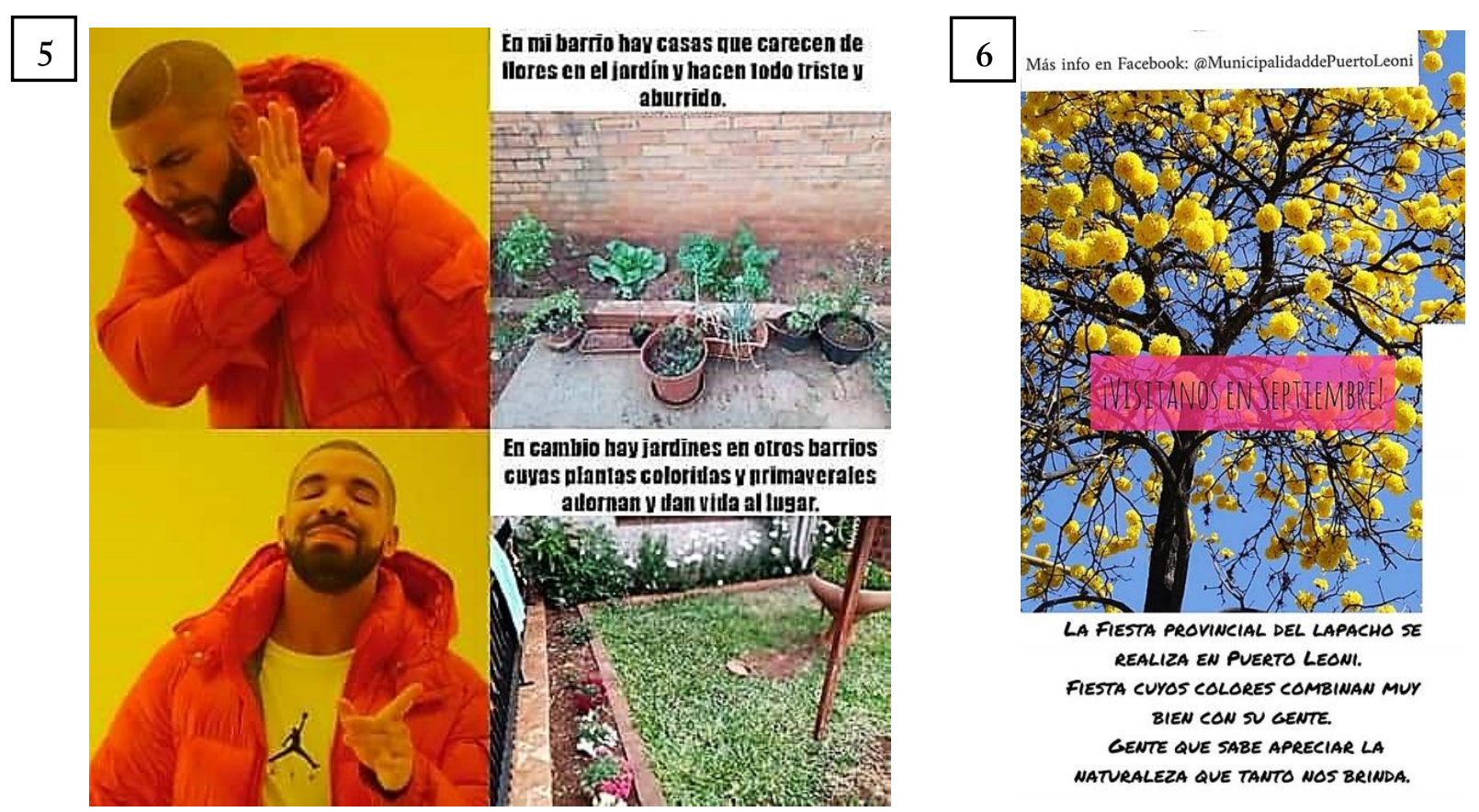

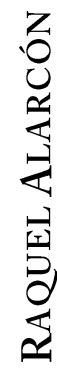

